\title{
Exploring Teachers' Knowledge and Students' Status about Dyscalculia at Basic Level Students in Nepal
}

\author{
Rajendra Kunwar ${ }^{1 *}$, Lekhnath Sharma ${ }^{2}$ \\ ${ }^{1}$ Tribhuvan University, Mahendra Ratna Multiple Campus, Ilam, NEPAL \\ ${ }^{2}$ Nepal Open University (NOU), Lalitpur, NEPAL
}

Received 17 June 2020 • Accepted 22 September 2020

\begin{abstract}
Dyscalculia refers to a specific and lifelong difficulty in learning mathematics. Dyscalculia has been observed among students from even basic levels of mathematical studies, and its effects regarding mathematical learning are serious. This study explores teacher knowledge and student status of dyscalculia at a basic level schools in Nepal. It was constructed by using the descriptive survey design. The study consists of 150 basic level school teachers and 500 students from llam Municipality, Ilam by using simple random sampling. To explore the teachers' knowledge about dyscalculia a mathematics learning difficulty test questionnaire has been used. Similarly, the status of dyscalculic students was measured by a dyscalculia screening test. The teachers were found to have inadequate knowledge regarding dyscalculia. The association between the teachers' knowledge and the demographic variables of gender, school type, and educational qualifications on dyscalculia were not found significant, except teaching experience. Consequently, the study revealed 6.8 percent of students were dyscalculic. Therefore, the concerned authority is recommended to improve teacher knowledge regarding dyscalculia for the proper identification, guidance, and intervention of the dyscalculic learner.
\end{abstract}

Keywords: learning difficulty, dyscalculia, basic level, teachers' knowledge

\section{INTRODUCTION}

\section{Background of the Study}

Mathematics is considered to be a difficult subject due to its abstract nature. Learning difficulty of mathematics is a global issue. It is considered an important and necessary subject in school education due to its everyday uses. Especially in mathematics and science, many students believe that it requires inborn ability or even brightness to achieve success, rather than persistence, well approaches, getting support from others, and learning over time (Hong \& Lin-Siegler, 2012). Therefore, it has long been given special attention in school education. However, not all expected outcomes in mathematics could be achieved to date, and negative student attitudes towards learning mathematics also could not be reduced. In school level education, teachers have a very important role to motivate students and create positive attitudes towards learning mathematics. They can assist students in overcoming their learning difficulties through intensive educational intervention. These difficulties or disabilities present in the learners' characteristics include cognitive and neuropsychological profiles, low linguistic skills, a lack of prerequisite knowledge and skills for mathematics learning, and learning difficulties or disabilities (Sharma, 2020). Hence, there exists a need for specialized instruction and proper intervention that goes beyond existing classroom instruction to reduce negative attitudes toward learning mathematics and improve performance. These interventions should focus on sound practice and best delivery of the intended outcomes. They should be effective, efficient, elegant, and must be based on sound principles of mathematics learning, reflecting the characteristics of the difficulty and focused on the practices that deliver the outcomes envisioned (Sharma, 2020).

In the context of Nepal, learning disability must be considered in terms of managerial practices and instructional priority in schools. Around 97 thousand

(c) $\mathbf{2 0 2 0}$ by the authors; licensee Modestum. This article is an open access article distributed under the terms and conditions of the Creative Commons Attribution License (http://creativecommons.org/licenses/by/4.0/). 


\section{Contribution to the literature}

- This study helps to create the equal opportunities in education to those learners who have learning disabilities due to dyscalculia through providing special support and feedback in order to provide the essential mathematical knowledge and skills.

- This study helps to distinguish between specific and general learning difficulty in mathematics that may cause due to the neurological conditions and other external factors.

- This study contributes to the literature about effective content delivery and special support to the students in mathematics to address the specific as well as general problems regarding teaching learning mathematics.

- The study provides the base line information of the teachers' knowledge about dyscalculic children and their status at primary schools in Nepal and other international context.

- The study suggests providing a basis for the educational policy makers and planners, administrators and teachers to reduce the problems related to teachers and students regarding dyscalculia in the holistic approach.

children having disabilities in Nepal are studying together with normal children in schools, while the number of children without school education due to disabilities is unknown (DoE, 2014). Students who have learning disabilities in mathematics are treated as normal students. As reported by the national population census report (CBS, 2014), 1.93 percent of the total population has some kind of learning disability in Nepal. The students with learning disabilities at basic level (grade 1 to 8 ) are 2.13 percent of the total enrollment in 2017 (MoE, 2018). In 2015 the constitution of Nepal provisioned free and compulsory primary education, and free secondary education, as fundamental rights, as well as the right to free education for disabled persons. Likewise, Nepal adopted the Disability Rights Act and an Inclusive Education Policy for persons with disabilities in 2017. The policy included provisions to educate all children with disabilities separately and without discrimination. Nepal's Disability Rights Act (2017) has provisions for special teacher training for those who educate children with disabilities to enhance knowledge and skills as well as to promote their access to quality education. It has also focused on developing specialized teachers for discipline and classroom management. Nevertheless, a huge mass of students is at the underperforming level, especially in mathematics (NASA, 2019) and thus have suffered from decreased mathematics achievement for some years. However, there is a need to enlighten the attitudes of students towards those with dyscalculia or disabilities to support their better performance.

\section{Overview of Learning Difficulty and Dyscalculia}

The term 'learning difficulty' is used to describe the general learning problems of students in the academic field. Likewise, the term dyscalculia also denotes learning problems in mathematics. It is a specific term used for mathematics learning disabilities. However, these two terms are not the same, but both terms are used in the field of education. Learning difficulties are treated as situational, not global, situated outside the child and resulting from specific causes, such as physical, educational, emotional, or environmental factors. Effective educational intervention for learning difficulties will improve their basic academic skills such as reading, writing, and mathematics and will result in the improvement of their achievement levels. On the other hand, dyscalculia is the term used when the cause of the learning disability is situated in the child's own cognitive development and is of neurological origin. It is lifelong and global and can be improved with welltargeted support and intervention (Hornigold, 2015). It is a specific kind of learning difficulty where the learners find difficulties in a specific area of learning; for example, reading or operating numbers or symbols. The child may have no particular problems in other areas. A child with a mathematics difficulty may perform well in reading, writing and speaking in other subject.

\section{Learning Difficulty}

Learning difficulties in mathematics have different forms, like difficulty in acquiring learning procedures, conceptual processes of fundamental concepts, or both together. Some students may have difficulty in any topic of arithmetic, algebra, or geometry (Chinn, 2016). Some students may exhibit the common mathematical difficulties in numerical and arithmetic deficiencies like counting and calculation (Hornigold, 2015). The environmental factors, such as low attendance, inappropriate way of teaching, lack of practice, poor curriculum, low standard of mastery of the subject matter, etc) create much higher difficulty in learning mathematics during the education (Sharma, 2020). Similarly, others have mathematics learning difficulties involving lagging in learning numbers, confusion in digits of numbers, difficulty in problem solving, understanding mathematical language, and forgetting the basic concepts of mathematics (Courtade, Test, \& Cook, 2015). 
Students' learning difficulties can be overcome through the appropriate intensive educational intervention used readily for a certain time. Learning difficulties are considered as resulting from specific causes, such as physical, educational, emotional, or environmental factors and can improve through effective educational intervention. Individuals who exhibit learning difficulties may not be intellectually impaired; rather, their learning problems may be the result of an inadequate design of instruction in curricular materials (Carnine, Jitendra, \& Silbert 1997). Mathematical difficulties refer to the poor mathematics achievement of the children caused by a variety of factors from poor instruction to environmental factors, but which are hypothesized to be due to an inherent weakness in mathematical cognition not attributable to socio cultural or environmental causes (Soares, Evans \& Patel, 2018). At some points, during the mathematics learning, some common mathematics difficulties may occur, such as remembering number facts and time tables, fractions, decimals, percentages and calculation, etc. Mostly, such difficulties can be defeated via additional support and a proper intervention. Such difficulty in mathematics does not necessarily mean dyscalculia (Hornigold, 2015). However, the use of appropriate methods and different effective models make the students' learning effective and favorable (Shalev, 2004).

\section{Dyscalculia}

The term 'dyscalculia' has Greek as well as Latin origins. The prefix 'dys' in Greek means 'badly', where as 'calculia', i.e. 'calculare' in Latin means to count (Khing, 2016). This indicates dyscalculia means to count badly however it seems to be more complex. The term dyscalculia was originally defined by the Czechoslovakian researcher Kosc (1974) as a difficulty in mathematics as a result of impairment to particular parts of the brain involved in mathematical cognition, but without a general difficulty in cognitive function. The term dyscalculia is used to describe specific difficulties with mathematics and is not a lack of intelligence, rather a difficulty to acquire the essential concepts that underpin skills in performing mathematical procedures (Glynis, 2013). Researchers have generally agreed that dyscalculia is taken as brain related condition, genetic cause, environment, brain differences, and working memory (Hornigold, 2015). It is a subject combining many different areas of study. An aspect has not been understood can nevertheless have an effect on other areas. According to Hornigold (2015) approximately $25 \%$ of students in a class are supposed to struggle with mathematics difficulties at different points in their studies. The usual difficulties in mathematics are: recalling number facts, time tables, backward counting, decimals and percentages, time telling, and calculations related to money and fractions. Most of such difficulties can be overcome with additional support and intensive intervention.

Mathematics cannot be separated from the particular cognitive processes in operation whenever minds are applied to a mathematical task (Sharma, 2020). Many people have mixed feelings about mathematics. Many students regard mathematics as a boring and disengaging subject (Colgan, 2014) and thus hate mathematics, and try to avoid it, which is a cause of mathematics anxiety. Mathematics is often expressed as a difficult subject that is inaccessible, uninteresting, and not for cool or engaging people, and not for girls (Boaler \& Dweck, 2016).A huge number of students in a widespread range have difficulties in understanding the complex concepts of mathematics (Brown et al., 2008). Likewise, there are several learner types that have an "extreme difficulty in mathematics" (Butterworth, 2005). Mathematics can be a very interesting, fun, and thought provoking subject for those learners who can enjoy their subject (Fu Sai, \& Chin Kin, 2017). Mathematics can also be a frustrating subject for many children who have problems with computation and application (Chinn, 2015). Thus, children with dyscalculia do not like to learn mathematics, and do not have fun with mathematical learning.

Dyscalculia is a specific learning difficulty affecting a person's mathematical learning capability. It is a neurological based disorder of mathematics abilities (Wadlington \& Wadlington, 2008). In the recent time, a strong correlation between dyscalculia and neurobiology have been begun to find by the researcher (Kucian \& Von Aster, 2015; Soares \& Patel, 2015). The term dyscalculia is frequently used as a synonymous term for learning disabilities in mathematics or arithmetic learning disorder (Devine, et al., 2013; Soares \& Patel, 2015). The prevalent range of dyscalculia is between 3-6 percent, (Kucian \& von Aster 2015) and the number of prevalence among females is greater than males, however there are opposing findings. Likewise, Hornigold (2015) states that around 6 percent of the population has dyscalculia with both girls and boys affected equally (Hudson \& English, 2016). However, the recent report stated by Sharma (2020) claims that the occurrence of specific learning difficulty (dyscalculia) in the population of school age children is about 6-8 percent, which conforms to Ardilla \& Roselli (2002). It shows that the percent of dyscalculic learners are increasing in the recent years. Dyscalculia is also known as 'difficulty with numbers', 'being bad at mathematics' or 'number blindness'. It is definitely a difficulty with numbers but should be considered a much deeperrooted problem than merely being bad at mathematics (Hornigold, 2015). It is further stated that dyscalculia is a specific difficulty with numbers, not with every branch of mathematics and can be improved with special support and intervention. The dyscalculic children have two types of problems, related to mathematical 
computation and reasoning (Khing, 2016). Mathematical computation related problems affect an individual's ability to solve mathematical calculations such as addition, subtraction, multiplication, and division problems. Such mathematical problems usually begin in basic level and continue through secondary level. However, this is a lifetime trouble the effects of which should not be ignored (Hornigold, 2015). Mathematical problems related to reasoning affect an individual while solving problems related to mathematical reasoning. People with dyscalculia have difficulty with operation of numbers and abstract concepts of time and direction. Dyscalculia is not only a result of improper teaching strategy, logical and sensory deficiency (Rubinsten \& Henik 2009; Rubinsten \& Tannock 2010); medical circumstances, cultural characteristics (Shalev \& Von Aster 2008) and deprive of motivation that may also have an effect on learning (Geary, 2006). The dyscalculic students have positive effects due to the aspects like particular intervention strategies together with individualized teaching (Butterworth, 2005; Re et al. 2014), the multisensory strategy (Attwood, 2010) and make different in appraisal (Little, 2009). Similarly, mathematical concepts can be taught effectively to students with mental disabilities via the use of computer software (Soykan \& Ozdamli, 2017) and computer assisted programs can help the students to increase the students' ability in reading (Akbari, Soltani-Kouhbanani \& Khosrorad, 2019).

\section{Teachers' Knowledge about Dyscalculia}

Teachers' knowledge about dyscalculia and dyscalculic students is essential for effective teaching. However, while it is not the result of improper pedagogy, proper methods of knowledge transformation used with such students having disability are necessary to provide remarkable intervention (Paula, Paulo, \& Cadime, 2016). The teachers at basic level have a vital role to identify the dyscalculic students' difficulties earlier and to provide them support for the intensive intervention. Teachers with adequate knowledge of detecting dyscalculic students, and of the intervention strategies, help the students to achieve at their ability level. On the other hand, appraisal and remediation of dyscalculic students are strongly associated with their personal capabilities and the weak points must be established before conducting any remedial attempt. Timely screening the dyscalculic students can have two-way benefits. On one hand they can be facilitated through the well-tailored intervention from suitably qualified teachers (Hornigold, 2015), On the other hand, they can be treated with multi-sensory teaching, using all three channels (visual, auditory and kinesthetic) simultaneously by the same class teacher. The use of different channels and methods with proper materials can help for better learning. As Hornigold (2015) stated, the more ways the information is presented, the more likely we are to remember it. Thus, the knowledge of the teacher about dyscalculia helps the learner to plan a detailed intervention program in a timely manner and that helps to support and alleviate their specific needs successfully.

\section{Significance of the Study}

Students with dyscalculia have specific mathematical learning difficulties in solving basic mathematical operations. Students with such specific mathematics learning problems show persistent and extreme difficulty in mathematics but functions well in other areas. Dyscalculia is a heterogeneous learning impairment affecting numerical and/or arithmetic functioning at behavioral, psychological, and neuronal levels (Kucian \& Von Aster, 2015). Additionally, it is further stated that a person suffered from disability may struggle for numerous effort to master a wide range of basic mathematical skills such as counting, numerical operations, arithmetic, transcoding between words, digits and quantities, and spatial number representation. Dyscalculia affects the learner more in early stages and during engagement with fundamental concepts of mathematics learning (Hornigold, 2015). As early as the first-grade students may start displaying negative attitudes towards learning mathematics and gradually develop mathematics anxiety. Moreover, schools have not given special attention to classroom delivery and the teaching learning strategies for the students with mathematics learning difficulty (Khing, 2016). On the other hand, students' performance in mathematics gradually decreases as students move to the upper grades.

All walks of life require the use of numerical information for grasping context, informing others, and resolving situations quickly. There are, however, a large number of students who may be struggling to learn mathematics, especially arithmetic, and who struggle with even the most basic numerical calculations and operations. The low achievement of students in mathematics in different grades at school level education is a serious issue. In such situations the number of students with dyscalculia might be one of the causes of this low achievement in mathematics. No researches in the field of mathematics learning disabilities, especially regarding dyscalculia, have been conducted in Ilam, Nepal. Thus, this study reveals information about the basic level teachers' knowledge about dyscalculia and the status of dyscalculic students at basic level schools in Ilam Municipality so that the teachers could help students with dyscalculia to overcome their difficulties and enjoy, rather than suffer, the time they spend in the mathematical activity.

The study can help concerned teachers, school headmasters, and educational planners and administrators to run and support dyscalculic students 
and implement the intensive educational interventions necessary to assist the students with learning disabilities that are missing due to the lack of knowledge and understanding of mathematics learning difficulty or dyscalculia, lack of support and other resources, and the perceived barriers that impact classroom instruction and supports (Graves, 2018). Likewise, this study provides a base for the concerned authorities of the local government to make policy and to train the concerned mathematics teacher with the specialized instruction training as required to meet the various needs of these specific dyscalculic students. This study can be a milestone in mathematics learning and also in the field of special education in Nepal.

\section{Objectives of the Study}

The objectives of this study are:

1. To find out the information of the basic level teachers' knowledge about their dyscalculic students.

2. To investigate the teachers' knowledge towards dyscalculic students at basic level in relation to gender, school type, educational qualification, and teaching experiences.

3. To identify the number of dyscalculic students studying at basic level.

\section{Hypotheses of the Study}

The null hypotheses of the study were formulated as:

1. Whether the teachers of basic level have low levels of knowledge about dyscalculia.

2. Whether the demographic variables of gender, school type, educational qualification and teaching experiences of basic level school teachers have no significant effects on their level of knowledge about dyscalculia.

3. Whether the number of dyscalculic students studying at basic level is high.

\section{METHODOLOGY}

\section{Research Design}

The study has adopted the quantitative survey design to investigate the teachers' knowledge about dyscalculia and the status of dyscalculic students studying at basic level in Ilam Municipality, Nepal. The survey design was used in the light of the nature of this study to accomplish the objectives and the hypothesis of the study.

\section{Population and Sample}

In this study, simple random sampling technique was employed to investigate the teachers' knowledge on dyscalculia and the number of dyscalculic students studying in both community and institutional school at basic level in Ilam Municipality, Province No. 1. In the course of the study, 150 basic level school teachers from 48 community and 15 institutional schools, and including both male and female teachers, of Ilam Municipality were selected as the sample for this study. Similarly, out of 150 basic level teachers, 114 teachers were from community schools and the remaining 36 teachers were from institutional schools. Likewise, 500 low performing students in mathematics studying at grade V and VI in Ilam Municipality were selected in order to find the number of dyscalculic students. In the random selection process students with high performance were omitted from the list of candidates. The list of the students for random selection was made with the help of the students' mathematics test scores or grades secured in the preceding class by the students themselves in school. In the sample selection procedure, the priority was given for selecting low performing or weak students in mathematics for the study. It was focused on selecting dyscalculic students, and persons with dyscalculia perform poorly in all areas of mathematics, particularly in the processing of numbers and quantities, in basic arithmetic operations, and in the solving of word problems (Haberstroh \& Schulte-Korne, 2019). Taking permission from the school administrations and the students themselves the survey instrument, a mathematics learning difficulty screening test, was used to collect the data related to dyscalculic students studying at basic level. On the other hand, a mathematics learning difficulty questionnaire was administered to the selected teachers.

\section{Development and Validation of Instruments}

In this study, a self-developed Mathematics Learning Difficulty Test (MLDT) questionnaire was used to measure the basic level school teachers' knowledge towards dyscalculia of the basic level students. The MLDT was formed by using the five factors related to the knowledge dimensions of dyscalculia. The factors of MLDT are: meaning and concept of dyscalculia, causes of dyscalculia, characteristics of dyscalculia, effects of dyscalculia, and intervention strategies of dyscalculia. In the beginning, 25 items containing 5 items from each factor were constructed. All items and factors of the questionnaire were reviewed by educational experts and university mathematics teachers to refine the weightage, adequacy and relevancy of the items in each factor. The questionnaire was translated into Nepali and then administered to a pilot group of 15 basic level school teachers. The pilot group of teachers was out of Ilam Municipality. After the pilot test some overlapping items were omitted and other unusual items were selected and rewritten for a final version. Thus, the final version of the questionnaire consists of 18 items containing all the factors. This final modified version of the questionnaire was also reviewed by the senior mathematics education 
Table 1. Summary Table of Teachers' Knowledge on Dyscalculia Test Items and Factors

\begin{tabular}{lcc}
\hline Factors Related to Dyscalculia & Factor wise Items & No of Items \\
\hline Meaning and concept of dyscalculia & 1,2 & 2 \\
Causes of dyscalculia & $3,4,7,8$ & 4 \\
Characteristics of dyscalculia & $5,6,13,14$ & 4 \\
Effects of dyscalculia & $9,10,15,16$ & 4 \\
Intervention strategies of dyscalculia & $11,12,17,18$ & 4 \\
Total no. of questions & & 18 \\
\hline
\end{tabular}

Table 2. Internal Consistency of the Teachers' Knowledge on Dyscalculia Test Factors

\begin{tabular}{lcc}
\hline Factors Related to Dyscalculia & No of Items & $\alpha-$ Value \\
\hline Meaning and concept of dyscalculia & 2 & 0.82 \\
Causes of dyscalculia & 4 & 0.80 \\
Characteristics of dyscalculia & 4 & 0.83 \\
Effects of dyscalculia & 4 & 0.82 \\
Intervention strategies of dyscalculia & 4 & 0.83 \\
Total no. of questions & 18 & 0.82 \\
\hline
\end{tabular}

Table 3. Summary Table of Dyscalculia Screening Test Items and Factors

\begin{tabular}{lll}
\hline Factors Related to Dyscalculia & Components of the Factor & No of Items \\
\hline Sequencing and recognizing & Inability to count backward & 3 \\
patterns & $\begin{array}{l}\text { Recalling number sequences } \\
\text { Applying rules and formula }\end{array}$ & $(4,5,6)$ \\
\hline Visual perception and processing & $\begin{array}{l}\text { Difficulty in time and direction } \\
\text { Reversal and isolations in writing numbers }\end{array}$ & $(1,2,3 \& 25)$ \\
\hline Memory retention & Inability to recall \& recognize words & 8 \\
& Inconsistent auditory memory & $(9,10,18,19,21,22,23 \& 24)$ \\
& Inconsistent visual memory & \\
\hline Motor skills & Difficulty in writing & 3 \\
& Difficulty in drawing & $(7,8 \& 26)$ \\
\hline Abstract reasoning & Solving word problem & 8 \\
& Ability to emphasized abstraction & $(11,12,13,14,15,16,17 \& 20)$ \\
\hline
\end{tabular}

researchers of Nepal. Thus, some modifications were further made according to their suggestions. Finally, the factor 'meaning and concept of dyscalculia' consists of two items. The remaining all four factors 'causes of dyscalculia', 'characteristics of dyscalculia', 'effects of dyscalculia', and 'intervention strategies of dyscalculia' consist of four items from each factors (Table 1). The questionnaire consisted of two parts. The first part consisted of demographic variables, namely gender, training, and the teaching experience of the teacher. The second part consisted of 18 items relating to the 5 different factors about dyscalculia. All the items in the questionnaire used a 3-point Likert scale: (3) adequate, (2) moderate, (1) inadequate. The validity of the questionnaire was established with the consultation and review of experts in the related fields.

The Cronbach Alpha was also calculated to determine the reliability of MLDT and was found to be 0.82 . The factor-wise alpha values are also given in Table 2. The reliability of the instrument was judged sufficient because the alpha value was well above 0.60 (Nunnally, 1967) which is the minimum requirement. This indicates that the instrument could be used to survey the data. The higher score shows higher teachers' knowledge towards dyscalculia and vice versa. Table 2 shows the reliability of the factors related to the knowledge dimension of dyscalculia.

Similarly, to find out the number of dyscalculic students studying at basic level, a well-tested instrument is required. The dyscalculic students can be screened using different types of tests like computer assisted instruments, quantitative surveys, and qualitative survey instruments. Among them, computer assisted tests can be used as a self-assessment tool by the students themselves, and it is easier and more effective for counting time, as well as visualizing pictures and symbols. However, adopting the computer assisted instrument to screen the basic level students' dyscalculia throughout the country is beyond current capabilities due to a lack of essential resources, technology, and operating skills. Hence, the instrument student dyscalculia screening tests' questionnaire was also developed by the investigator to measure the number of dyscalculic students at basic level. The instrument Dyscalculia Screening Test (DST) questionnaire was based on the five factors related to the knowledge dimensions of dyscalculia (Table 3).

The test items of the instrument DST were constructed considering the five factors given in Table 3. 
Table 4. Internal Consistency of the Dyscalculia Screening Test Factors

\begin{tabular}{lcc}
\hline Factors Related to Dyscalculia & No of Items & Alpha $(\alpha)-$ Value \\
\hline Sequencing and recognizing patterns & 3 & 0.82 \\
Visual perception and processing & 4 & 0.85 \\
Memory retention & 8 & 0.84 \\
Motor skills & 3 & 0.85 \\
Abstract reasoning & 8 & 0.84 \\
Total & 26 & 0.84 \\
\hline
\end{tabular}

Table 5. Teachers' Knowledge Scores about Dyscalculic Students

\begin{tabular}{|c|c|c|c|c|c|c|}
\hline \multirow{2}{*}{ Knowledge Domain/ Factors } & \multirow{2}{*}{ Maximum Scores } & \multicolumn{3}{|c|}{ Level of Knowledge } & \multirow{2}{*}{ Mean } & \multirow{2}{*}{ SD } \\
\hline & & Good & Average & Poor & & \\
\hline Meaning and concept of dyscalculia & $6(11.11 \%)$ & $12(8 \%)$ & $101(67.33 \%)$ & $37(24.66 \%)$ & 2.8 & 0.97 \\
\hline Causes of dyscalculia & $12(22.22 \%)$ & $10(6.66 \%)$ & $48(32 \%)$ & $92(61.33 \%)$ & 3.60 & 1.15 \\
\hline Characteristics of dyscalculia & $12(22.22 \%)$ & $35(23.33 \%)$ & $90(60 \%)$ & $25(16.66 \%)$ & 4.58 & 1.02 \\
\hline Effects of dyscalculia & $12(22.22 \%)$ & $42(28 \%)$ & $89(59.33)$ & $19(12.66 \%)$ & 4.86 & 1.26 \\
\hline Intervention strategies of dyscalculia & $12(22.22 \%)$ & $30(20 \%)$ & $78(52 \%)$ & $42(28 \%)$ & 3.98 & 0.98 \\
\hline Overall & $54(100 \%)$ & $129(17.19 \%)$ & $406(54.13 \%)$ & $215(28.66 \%)$ & 19.82 & 5.38 \\
\hline
\end{tabular}

The test items in DST were related to assess the dot enumeration, number comparison, computational skills, mathematics facts and operations, quantitative reasoning, problem solving, and visual spatial and symbolic abstraction. In the initial stage, the questionnaire was constructed with 32 items. Of these, 23 items were multiple choice type and 9 were of a close ended type related to drawing and writing. For the establishment of validity and reliability the questionnaire was piloted with group of 24 students studying at grade five and six in Ilam municipality. The difficulty level and discrimination index were also maintained using item analysis of the multiple-choice type items. The instrument DST is also a kind of speed test, so the average time to complete the questionnaire was also measured while piloting the test and it was thus fixed to 30 minutes for the test administration. This also conformed to Butterworth (2005); when screening the dyscalculic students of aged 10-14 years the administration time is $15-30$ minutes. The questionnaire was also reviewed by the senior high school mathematics teacher and university mathematics professors and finally 6 weak and overlapping items were rejected from the questionnaire. Thus, the final set of the questionnaire consists of 26 items, wherein 17 items were multiple choices and 9 items were related to drawing and writing from different 5 factors as given in Table 4. The instrument DST consists of 32 marks. Similarly, Cronbach alpha was also calculated, and the five factor-wise internal consistencies were also found to be positive (Table 4). Thus, the questionnaire adopted the process of standardization and the content validity was also established with consultation of the subject experts.

\section{Data Analysis Procedures}

In this section, the data obtained from the quantitative survey are analyzed using descriptive as well as inferential statistics. The descriptive statistics included percentages, means, standard deviations, and also inferential statistics including the Chi-square test. The data thus collected were analyzed using SPSS Version 22. Frequency and percentage distribution were used to determine the teachers' level of knowledge and find out the students' dyscalculia screening test scores. The Chi-square test was used to associate the basic level school teachers' knowledge in terms of demographic variables such as genders, school types, educational qualifications, and teaching experiences.

\section{RESULTS AND DISCUSSION}

\section{Teachers' Knowledge Scores about Dyscalculic Students}

The teachers' knowledge scores about dyscalculic students in the given five knowledge domains are shown in Table 5. This table describes the maximum score of the domain, level of knowledge, mean and standard deviation in overall aspects and also domain-wise aspects of knowledge. The maximum score of the overall aspect of knowledge domain was 54 with the mean score 19.82 and SD of 5.38. The majority of the teachers, 406 $(54.13 \%)$ were found to be at the level of average knowledge. A majority of teachers, 101 (67.33\%), 90 $(60 \%), 89(59.33 \%)$ and $78(52 \%)$ have an average level of knowledge about the meaning and concept of dyscalculia, characteristics of dyscalculia, effects of dyscalculia, and intervention strategies of dyscalculia respectively. But the majority of teachers, 92 (61.33\%) were found to be poor in the level of knowledge in the domain causes of dyscalculia. No one's knowledge domain was found at a good level of knowledge for the basic level teacher. Only $129(17.19 \%)$ of the respondents were found at good level of knowledge in overall knowledge domain. Thus, the null hypothesis that 
Table 6. Association of Basic Level Teachers' Knowledge with their Demographic Variables

\begin{tabular}{|c|c|c|c|c|c|c|c|c|}
\hline \multirow[t]{2}{*}{ Demographic variables } & \multirow[t]{2}{*}{ Categories } & \multicolumn{2}{|c|}{ Level of Knowledge } & \multirow[t]{2}{*}{$\mathrm{N}$} & \multirow[t]{2}{*}{$\mathrm{df}$} & \multicolumn{2}{|c|}{ Test Statistics } & \multirow[t]{2}{*}{ Inference } \\
\hline & & Average & Poor & & & Chi Sq. & $\mathrm{P}$ value & \\
\hline \multirow{2}{*}{ Gender } & Male & 24 & 32 & 56 & \multirow{2}{*}{1} & \multirow{2}{*}{$X^{2}=1.83$} & \multirow{2}{*}{$\mathrm{p}=0.176$} & Not \\
\hline & Female & 51 & 43 & 94 & & & & Significant \\
\hline \multirow{2}{*}{ School type } & Community & 76 & 38 & 99 & \multirow{2}{*}{1} & \multirow{2}{*}{$X^{2}=0.37$} & \multirow{2}{*}{$\mathrm{p}=0.541$} & Not \\
\hline & Institutional & 22 & 12 & 51 & & & & Significant \\
\hline \multirow{2}{*}{ Educational qualification } & SLC & 6 & 3 & 9 & \multirow{2}{*}{1} & \multirow{2}{*}{$X^{2}=0.11$} & \multirow{2}{*}{$\mathrm{p}=0.734$} & Not \\
\hline & Above SLC & 86 & 55 & 141 & & & & Significant \\
\hline \multirow{2}{*}{ Teaching experiences } & Below 5 years & 13 & 17 & 30 & \multirow{2}{*}{1} & \multirow{2}{*}{$\chi^{2}=5.99$} & \multirow{2}{*}{$\mathrm{p}=0.014$} & \multirow{2}{*}{ Significant } \\
\hline & Above 5 years & 81 & 39 & 120 & & & & \\
\hline
\end{tabular}

$\mathrm{P}$ at $5 \%$ Significance Level

whether the teachers of basic level have low level of knowledge about dyscalculia is accepted.

The scenario of the teachers' knowledge about dyscalculic children at basic level is very poor in regard to the knowledge domain and their level of knowledge. The overall knowledge of 215 (28.66\%) basic level teachers were found at the poor level of knowledge about dyscalculia. The overall score of the teachers at the average level of knowledge, 406 (54.13\%), confirmed that the basic level teachers had average knowledge about dyscalculia, which proved the results of Kamala \& Ramganesh (2013).The present study shows that a majority of teachers have no good level of knowledge regarding dyscalculia. These findings are consistent with the earlier research by Ghimere (2017), which explained that a majority, $79(52.67 \%)$, of the primary school teachers had moderately adequate knowledge and 71 $(47.33 \%)$ had inadequate knowledge regarding learning difficulty or dyscalculia. The study reported that the primary school students suffering from dyscalculia in Malaysia was 5.5 percent (Wong et al., 2014), as determined by computer assisted screener, whereas Emerson, Babtie and Butterworth (2010); Thompson (2017) found 5 percent dyscalculic children. Similarly, as stated by Fu Sai and Chin Kin, (2017), the teachers in Malaysia have a low level of awareness of dyscalculia as $57.5 \%$ of the teacher did not know what dyscalculia actually is and had limited knowledge of the characteristics of dyscalculia, with the topic of dyscalculia rarely being discussed in their teaching field. Similar findings were also found by Dias et al., (2013) that the participating educators had very little specific knowledge on dyscalculia. The finding of Shari and Vranda (2016); Karasakal (2018) also affirmed that the teachers were found with a lack of awareness about dyscalculia. Consequently, support for mathematics teachers about their gap of required subject matter knowledge, supports for important resources that is needed to provide effective instruction to the students with mathematical learning disabilities is essential (Graves, 2018).

\section{Teachers' Knowledge with Demographic Variables (Gender, School Type, Educational Qualification, and Teaching Experiences)}

Table 6 envisages the outcome of Chi-square analysis to bring out the association between the knowledge of basic level teachers with their demographic variables. The teachers by their gender, the Chi-square test $\chi^{2}=1.83$ and $p=0.176$ at 0.05 level of significance, $(p>0.05)$ did not reveal a statistically significant difference about the knowledge of dyscalculic students. Similarly, the Chisquare test on school type $x^{2}=0.37$ and $p=0.541$ at 0.05 level of significance, $(p>0.05)$ and in educational qualification, $\chi^{2}=0.11$ and $p=0.734$ at 0.05 level of significance, $(p>0.05)$ shows that the differences of teachers by school type and educational qualification respectively were not found statistically significant. Thus, the null hypothesis whether the demographic variables of gender, school type, and educational qualification of basic level school teachers have no significant effect on their level of knowledge about dyscalculia is accepted. There is no difference in the teachers' level of knowledge about dyscalculia due to the effects of these variables. However, for the teaching experiences of the teacher at basic level above 5 years of teaching experience, the chi square test $\chi^{2}=5.99$ and $p=$ 0.014 at 0.05 level of significance, $(p<0.05)$ were found significant. Thus, the null hypothesis is accepted and significantly different on level of knowledge about dyscalculia is determined. Hence the teaching experience has a significant effect on the teachers' knowledge about dyscalculia. The results showed that the intense knowledge about dyscalculia is found in more experienced teachers.

The findings that the knowledge of basic level teachers on dyscalculia in relation to the demographic variables gender, school type and educational qualification are consistent with the findings of the previous research of Lingeswaran (2013); Ghimere (2017), that the association between the knowledge of primary school teachers and their demographic variables as: gender, educational qualifications, school type, and teaching experience about learning disabilities were found to be statistically significant as their $p$-values 
Table 7. Students Dyscalculia Screening Test Scores

\begin{tabular}{lccc}
\hline Range of Scores & No of Students & Students in Percentage & Level of Score \\
\hline $0-8$ & 34 & $6.8 \%$ & Low Level \\
$8-16$ & 132 & $26.4 \%$ & Average Level \\
$16-24$ & 206 & $41.2 \%$ & High Level \\
$24-32$ & 128 & $25.6 \%$ & \\
\hline
\end{tabular}

were below the level of significance of 0.05 . Similarly, the variable years of teaching experience was not found significant for their level of knowledge. Consequently, the findings are consistent with the earlier research by Hudson and English (2016); Wong et al. (2016) that the effect of dyscalculia was found equally in either gender, while the findings of the study were contrary with the results of Alahmadi and El Keshky (2018).

\section{Students Dyscalculia Screening Test Scores}

To analyze the status of dyscalculic students, the test scores of DST of basic level students were arranged in the form of continuous series at the interval of 8-unit scores. The total scores were divided into 4 equal intervals with a range of $25 \%$ in percentile. As Chinn (2015) stated, the low achievement in mathematics is usually taken to be an achievement level below the 25th percentile. Thus, the 25 th percentile score constitutes the low achievement level, and those between the 25th and 75th percentile score constitute average or moderate achievement level, and the score above $75 \%$ is considered the high achieving level. In this study the score below $25 \%$ is used as the benchmark for categorizing the dyscalculic students. Table 7 shows the position of basic level students' scores at grade V and VI in dyscalculic screening tests conducted by the investigator.

The test scores of the students' dyscalculia screening test in Table 7 shows that $25.6 \%$ of students found at the level of high score as defined by the investigator. In the same way, $67.6 \%$ of students were found at the level of average scores and $6.8 \%$ of students found at the low level of score in the dyscalculia screening test. This dyscalculia screening test scores indicates that majority of the students are in the average performance level. Similarly, nearly one fourth of the students are found at high level and the least number of students $(6.8 \%)$ are found at the low level in the dyscalculic screening test. These students with low level of performance are categorized as the dyscalculic students. Thus, the null hypothesis of whether the number of dyscalculic students studying at basic level is high is rejected. It is not so high with regard to the international researchers' assertion.

The result of this study is consistent with the result (6.67 \%) of Adhikari (2014). This is similar to most international findings about dyscalculic students such as the prevalence range of dyscalculia lies between 3-6 percent, Kucian and Von Aster (2015). Hornigold (2015); (Hudson \& English, 2016) state around 6\% of the population has dyscalculia with boys and girls affected equally. Sharma (2020) states that the occurrence of specific learning difficulty (dyscalculia) in the population of school age children is about 6-8 percent, which also conformed to Ardilla and Roselli (2002). However, a recent study on the primary level students conducted in India revealed 9\% of students were found to have dyscalculia (Jeya \& Albina, 2019). Considering these findings, it can be concluded that the range of dyscalculic learners lies at the range of 3-9 percentage. Thus, the result of the students' status about dyscalculia $(6.8 \%)$ lies on the range as discussed above.

\section{CONCLUSIONS}

Mathematics is a cumulative subject consisting of many different branches. If one aspect has not been understood properly, it can have an effect on other areas. Mathematics is considered a difficult subject due to its intrinsic qualities, seemingly abstract nature, and the weak mathematical backgrounds and attitudes towards mathematics of learners. Such difficulties can be overcome with proper extra support and effective intervention. This type of difficulty in mathematics does not necessarily mean dyscalculia. Dyscalculia is a specific learning difficulty affecting a person's mathematical ability throughout life. It is much more deeply rooted than simple mathematical weakness. Affected learners show persistent and extreme difficulty in mathematics. The dyscalculic learner can achieve success through individualized and intensive learning strategies that enable individuals to achieve at their ability level. In the context of Nepal, there are some researches relating to the learning disabilities, however, these do not focus on dyscalculia. Thus, there is an opportunity for the teachers of Nepal to play an important role in detecting and assisting the dyscalculic students, and providing proper differentiated learning strategies that overcome their learning difficulties and help the students to enjoy learning mathematics rather than suffer.

The study on the teachers' knowledge about dyscalculic students in five knowledge domains, or factors, revealed that the majority of the teachers were found to be at the average level of knowledge. Unfortunately, a very low number of teachers were found to be at a good level of knowledge in the overall knowledge domain. This shows that a maximum numbers of students suffering from dyscalculia are neither getting help from the teacher due to the lack of teachers' knowledge about dyscalculic students. The 
study also found that there is no association among the demographic variables of gender, school type, and educational qualification on the teachers' knowledge of basic level about dyscalculia. However, the teachers' teaching experience was found to be a good predictor on the teachers' knowledge of dyscalculia. This indicates that more experienced teachers have more knowledge about dyscalculia. This also discloses that either most teachers have never attended in-service or pre-service training courses, or the topic 'dyscalculia' has not been introduced in the training courses. In the same way, the teachers may have a poor level of knowledge about dyscalculia as it has not been incorporated in the academic courses. The study also concludes that the numbers of dyscalculic students studying at basic level are found to be in alignment with the international assertion. However, it is necessary to address the problem related to dyscalculia, and more attention should be given to provide essential knowledge to the basic level teachers of Nepal to create proper mathematics learning environments and to enable teachers to help students with dyscalculia to overcome their learning difficulties and make their learning enjoyable so as to support inclusive principles of mathematics education.

In a nutshell, it can be concluded that the condition of the teachers' knowledge on dyscalculia is at an alarming condition. Thus, the concerned authorities need to invest in teachers training about learning difficulties and the learning disability in order to boost up teachers' knowledge and efficacy to identify possible signal of dyscalculia. Furthermore, topics like dyscalculia, learning disabilities, and other recent knowledge should also be incorporated in the content of academic and training courses.

\section{ACKNOWLEDGEMENTS}

This study was funded by University Grant Commission, Sanothimi Bhaktapur, Nepal. The researcher, therefore, acknowledges the UGC, Nepal with thanks for their financial support.

\section{REFERENCES}

Adhikari, K. (2014). Assessment of the awareness of dyscalculia among dyscalculia primary teachers: a case study of Chuhandanda VDC (Unpublished master's thesis). Tribhuvan University, Kirtipur, Nepal.

Akbari, E., Soltani-Kouhbanani, S., \& Khosrorad, R. (2019). The effectiveness of working memory computer assisted program on executive functions and reading progress of students with reading disability disorder. Electronic Journal of General Medicine, 16(2), em123. https://doi.org/10.29333/ ejgm/94044
Alahmadi, N. A., \& El Keshky, M. (2018). Assessing primary school teachers' knowledge of specific learning disabilities in the Kingdom of Saudi Arabia. Journal of Educational and Developmental Psychology, 9(1), 9-22. https://doi.org/10.5539/ jedp.v9n1p9

Ardilla, A., \& Rosselli, M. (2002). Acalculia and dyscalculia. Neuropsychology Review, 12(4), 179-231. https:/ / doi.org/10.1023/A:1021343508573

Attwood, T. (2010). Dyscalculia minus understanding equals problem. Special Educational Needs Magazine, 47, 86-87.

Boaler, J., \& Dweck, C. S. (2016). Mathematical mindsets: Unleashing students' potential through creative math, inspiring messages and innovative teaching. San Francisco, CA: Jossey-Bass.

Brown, M., Brown, P., \& Bibby, T. (2008). I would rather die: Reasons given by 16- years-olds for not continuing their study of mathematics. Research in Mathematics Education, 10(1), 3-18. https:/ / doi.org/ 10.1080/14794800801915814

Bugden, S., \& Ansari, D. (2015). How can cognitive developmental neuroscience constrain our understanding of developmental dyscalculia? In S. Chinn (Ed.). The Routledge International Handbook of Dyscalculia and Mathematical Learning Difficulties (pp. 18-43). London, United Kingdom: Routledge.

Butterworth, B. (2005). The development of arithmetical abilities. Journal of Child Psychology and Psychiatry, 46(1), 3-18. https:// doi.org/10.1111/j.14697610.2005.00374.x

Cappelli, L. F. (2018). Student handbook 2018-2019. Disability Services Office. Camden County College. USA.

Carnine, D., Jitendra, A., \& Silbert, J. (1997). A descriptive analysis of mathematics curricular materials from a pedagogical perspective. Remedial and Special Education, 18, 66-81. https://doi.org/ $10.1177 / 074193259701800201$

CBS, (2014). Population Monograph of Nepal (Vol. II). Kathmandu, Nepal: Central Bureau of Statistics.

Chinn, S. J. (2015). The Routledge international handbook of dyscalculia and mathematical learning difficulties. Abingdon, Oxon: Routledge/Taylor \& Francis Group. https:/ / doi.org/10.4324/9781315740713

Colgan, L. (2014). Making math children will love: Building positive mathitudes to improve student achievement in mathematics. What works? Research into Practice Research Monograph 56. Student Achievement Division, Ontario Ministry of Education. Retrieved from http://www.edu.gov.on.ca/eng/literacynu meracy/inspire/research/WW_MakingMath.pdf

Cortiella, C., \& Horowitz, S. H. (2014). The state oflearning disabilities: facts, trends and emerging issues. New York: National Center for Learning Disabilities. 
Courtade, G. R., Test, D. W., \& Cook, B. G. (2015). Evidence-based practices for learners with severe intellectual disability. Research and Practice for Persons with Severe Disabilities, 39(4), 305-318. https: / / doi.org/10.1177/1540796914566711

Devine, A., Soltész, F., Nobes, A., Goswami, U., \& Szucs, D. (2013). Gender differences in developmental dyscalculia depend on diagnostic criteria. Learning and Instruction, 27(n), 31-39. https://doi.org/ 10.1016/j.learninstruc.2013.02.004

DoE \& DIRD (2014). Analyzing educational status of children with disability and identifying critical intervention to promote their enrollment, retention and success in school. Retrieved from https://www.doi.gov.np

Fu, S. H., \& Chin, K. E. (2017). An online survey research regarding awareness of Dyscalculia among educators in Sandakan district, Sabah. International Journal of Academic Research in Progressive Education and Development, 6(2), 1-10. https://doi.org/ 10.6007/IJARPED/v6-i2/2891

Fuchs, L. S., Fuchs, D., \& Speece, D. L. (2002). Treatment validity as a unifying construct for identifying learning disabilities. Learning Disability Quarterly, 25, 33-45. https:/ / doi.org/10.2307/1511189

Geary, D. (2004). Mathematics and learning disabilities. Journal of Learning Disabilities, 37(1), 4-15. https: / / doi.org/10.1177/00222194040370010201

Geary, D. C. (2006). Dyscalculia at an early stage: characteristics and potential influence on socioemotional development. In R. E. Tremblay, R. G. Barr, \& R. D. Peters (Ed.), Encyclopaedia on Early Childhood Development (pp. 1-4). Montreal: Centre of Excellence for Early Childhood Development.

Ghimere, S. (2017). Knowledge of primary school teacher regarding learning disabilities in school children. Journal of Nobel Medical College. https://doi.org/ 10.3126/jonmc.v6i1.18084

Glynis, H. (2013). Dyscalculia: action plans for successful learning in mathematics (2nd ed.). London: Routledge.

Graves, T. (2018). Teacher knowledge and perception of mathematics disabilities and dyscalculia.SMTC Plan B Papers. 71. http:/ / repository.uwyo.edu/smtc_plan _b/71

Haberstroh, S., \& Schulte-Korne, G. (2019).The diagnosis and treatment of dyscalculia. Deutsches Arzteblatt international, 116(7), 107-114. https://doi.org/ 10.3238/arztebl.2019.0107

Hong, H., \& Lin-Siegler, X. (2012). How learning about scientists' struggles influences students' interest and learning in physics. Journal of Educational Psychology, 104, 469-484. https://doi.org/10.1037/ a0026224
Hornigold, J. (2015). Dyscalculia: pocketbook. Teachers' Pocketbooks, UK.

Jeya, A. A., \& Albina, A. P. (2019). A study of students with dyscalculia and their mathematical abilities at primary schools in Karaikudi. PEOPLE: International Journal of Social Sciences, 4(3), 15331542. https://doi.org/10.20319/pijss.2019.43. 15331542

Kamala, R., \& Ramganesh, E. (2013). Knowledge of specific learning disabilities among teacher educators in Puducherry, Union Territory in India. International Review of Social Sciences and Humanities, 6(1), 168-175.

Karasakal, M. (2018). Promoting primary school teachers' awareness of dyscalculia (Unpublished master's thesis). The Graduate School of Education of Ihsan Dogramaci Bilkent University.

Kaufmann, L. (2008). Dyscalculia: neuroscience and education. Educational Research, 50(2) 163-175. https:/ / doi.org/10.1080/00131880802082658

Khing, B. (2016). Dyscalculia: its types, symptoms, causal factors, and remedial programs. Learning Community, 7(3), 217-229. https://doi.org/10.5958 /2231-458X.2016.00022.1

Kosc, L. (1974). Developmental dyscalculia. Journal of Learning Disabilities, 7(3), 46-59. https://doi.org/ $10.1177 / 002221947400700309$

Kucian, K., \& Von Aster, M. (2015).Developmental dyscalculia. European Journal of Pediatrics, 174(1), 113. https:/ / doi.org/10.1007/s00431-014-2455-7

Lenhard, W., \& Lenhard, A. (2013). Learning difficulties. In L. Meyer (Ed.), Oxford Bibliographies in Education. New York: Oxford University Press. https:/ / doi.org/10.1093/obo/9780199756810-0115

Lingeswaran, A. (2013). Assessing knowledge of primary school teachers on specific learning disabilities in two schools in India. Journal of Education and Health Promotion, 2. https:/ / doi.org/10.4103/2277-9531.115807

Little, M. E. (2009). Teaching mathematics: issues and solutions. Teaching Exceptional Children Plus, 6(1), 115.

MoE. (2018). Education in figures 2017: at a glance report. Kathmandu: Ministry of Education, Science \& Technology.

NASA. (2019). Report on the National Assessment of Student Achievement (Grade 5: Mathematics and Nepali), Sanothimi: Education Review Office.

Nunnally, J. C. (1967). Psychometric theory. New York: McGraw-Hill.

Paula, S., Paulo, C. D., \& Cadime, I. (2016). Predictors of primary school teachers' knowledge about developmental dyscalculia, European Journal of 
Special Needs Education, 32(2), 204-220. https:/ / doi.org/10.1080/08856257.2016.1216635

Price, G., \& Ansari, D. (2013). Dyscalculia: characteristics, causes, and treatment. Numeracy, 6(1), 1-16. https:/ / doi.org/10.5038/1936-4660.6.1.2

Re, A. M., Pedron, M., Tressoldi, P. E., \& Lucangeli, D. (2014). Response to specific training for students with different levels of mathematical difficulties. Exceptional Children, 80(3), 337-352. https:// doi.org /10.1177/0014402914522424

Rubinsten, O., \& Henik, A. (2009). Developmental dyscalculia: heterogeneity might not mean different mechanisms. Trends in Cognitive Sciences 13(2), 92-99. https://doi.org/10.1016/j.tics.2008. 11.002

Rubinsten, O., \& Tannock, R. (2010). Mathematics anxiety in children with developmental dyscalculia. Behavioral and Brain Functions, 6(46), 113. https:// doi.org/10.1186/1744-9081-6-46

Shalev, R. (2004). Developmental dyscalculia. Journal of Child Neurology, 19(10), 765-771. https://doi.org/ $10.1177 / 08830738040190100601$

Shalev, R. S., \& M. G. Von Aster. (2008). Identification, classification, and prevalence of developmental dyscalculia. In Encyclopaedia of Language and Literacy Development (pp. 1-9). London: Canadian Language and Literacy Research Network.
Shari, M., \& Vranda, M. N. (2016). Attitude of primary school teachers towards children with learning disabilities Journal of Indian Association of Child Adolescent Mental Health, 12(4), 323-335.

Sharma, M. (2020). Mathematics for all. Mathematics education workshop series at Framingham State University. Mathematics Education Workshop Series.

Soares, N., \& Patel, D. (2015). Dyscalculia. International Journal of Child and Adolescent Health, 8(1), 15-26. Retrieved from http://libproxy.uwyo.edu/login/ ?url=https:/ / searchproquest-

Soares, N., Evans, T., \& Patel, D. R. (2018). Specific learning disability in mathematics: a comprehensive review. Translational Pediatrics, 7(1), 48-62. https://doi.org/10.21037/tp.2017.08.03

Soykan, E., \& Ozdamlı, F. (2017). Evaluation of the android software for special needs children. Eurasia Journal of Mathematics, Science and Technology Education, 13(6), 2683-699. https:/ / doi.org/10.12973/eurasia.2017.01247a

Wadlington, E., \& Wadlington, P. (2008). Helping students with mathematical disabilities to succeed. Preventing School Failure: Alternative Education for Children and Youth, 53(1), 2-7. https://doi.org/ 10.3200/PSFL.53.1.2-7

\section{http://www.ejmste.com}

